\title{
Rendimento de grãos em feijão preto: o componente que mais interfere no valor fenotípico é o ambiente
}

\author{
Grain yield in black beans: environment is the component that more interferes in the phenotypic value
}

\author{
Juliano Garcia Bertoldo $^{\text {I* }}$ Jefferson Luís Meirelles Coimbra' $^{\text {II }}$ Altamir Frederico Guidolin ${ }^{\text {II }}$ \\ Rubens Onofre Nodari ${ }^{\mathrm{I}}$ Haroldo Tavares Elias ${ }^{\mathrm{III}}$ Leire Daiane BariliII Naine Martins do Vale ${ }^{\mathrm{II}}$ \\ Diane Simon RozzettoII
}

\section{RESUMO}

O objetivo deste trabalho foi avaliar os componentes da variância fenotípica para o caráter rendimento de grãos a fim de gerar informações que auxiliem o melhoramento de plantas e verificar a sensibilidade genotípica entre genótipos de feijão do grupo preto. Para tanto, foi avaliado o caráter rendimento de grãos de 12 genótipos de feijão em 10 ambientes do Estado de Santa Catarina, por meio do método REML/BLUP. A decomposição dos componentes da variância fenotípica permitiu ampliar as inferências sobre os resultados obtidos para o caráter rendimento de grãos além daquelas tradicionalmente utilizadas na avaliação de linhagens. O genótipo BRS Campeiro foi o que apresentou maior média de rendimento de grãos e ainda o que obteve o maior valor predito, podendo ser indicado para todos ambientes avaliados. Nos ambientes 1 (2004/ Canoinhas), 2 (2005/Canoinhas), 9 (2004/Ponte Serrada) e 10 (2005/Ponte Serrada), o valor de rendimento de grãos, em todos os genótipos avaliados, foi acima da média geral. Os genótipos CHP 9858, CHP 9859, CHP 9954 e CHP 9965 revelaram uma adaptabilidade específica ao ambiente 6 (2005/Ituporanga).

Palavras-chave: Phaseolus vulgaris L., variância fenotípica, interação $G x E$, REML/BLUP.

\section{ABSTRACT}

This study aimed to evaluate the phenotypic variance components for grain yield characters on the sense to be useful for breeding programs, and verify the genetic sensibilility among genotypes of black beans group. The grain yield character was evaluated in twelve black beans genotypes in ten environments of the Santa Catarina Estate through the REML / BLUP method. With the phenotypic variance components decomposition it was possible to provide additional information than traidicionally utilized in line evaluations for grain yield character. The highest grain yield average and the highest predicted value was obtain at genotype BRS Campeiro, which may be suitable for all evaluated environments. In the environments 1 (2004/Canoinhas), 2 (2005/Canoinhas), 9 (2004/Ponte Serrada) e 10 (2005/Ponte Serrada) higher grain yield has been obtained above general mean in all evaluated genotypes. The genotypes CHP 9858, CHP 9859, CHP 9954 and CHP 9965 presented specific adaptability to environment 6 (2005/Ituporanga).

Key words: Phaseolus vulgaris L., phenotypic variance, interaction $G \times E, R E M L / B L U P$.

\section{INTRODUÇÃO}

O feijão (Phaseolus vulgaris L.) é a espécie mais cultivada no mundo entre as do gênero Phaseolus, tendo o Brasil como o maior produtor e ao mesmo tempo o maior consumidor (BERTOLDO et al., 2008). De modo geral, o principal objetivo dos programas de melhoramento é a obtenção de genótipos com maior potencial produtivo e com características agronômicas desejáveis e insensíveis às variações de ambiente, denominadas de caraterísticas superiores. Além da melhoria no rendimento de grãos, muitos programas

IPrograma de Pós-graduação em Recursos Genéticos Vegetais, Centro de Ciências Agrárias (CCA), Universidade Federal de Santa Catarina (UFSC). Rod. Admar Gonzaga, 1346, 88034-001, Florianópolis, SC, Brasil. E-mail: jgbertoldo@gmail.com.*Autor para correspondência.

"Universidade do Estado de Santa Catarina (UDESC), Centro de Ciências Agroveterinárias Instituto de Melhoramento e Genética Molecular (IMEGEM), Lages, SC, Brasil.

IIICentro de Pesquisa para Agricultura Familiar (EPAGRI), Chapecó, SC, Brasil. 
de melhoramento objetivam a melhora nas qualidades nutricionais e em outras características de valor comercial em plantas (MOOSE \& MUMM, 2008). O resultado final é a criação de um genótipo melhorado, de modo que a seleção visa acumular alelos favoráveis para a característica de interesse (COIMBRA et al., 2008). Porém, no Brasil, os programas de melhoramento de feijão no Brasil têm enfocado, principalmente, o caráter rendimento de grãos, objetivando um aumento significativo na produção sem incrementar a área plantada, e não as qualidades culinárias. Porém, umas das dificuldades do melhorista, no que se refere à seleção de uma determinada planta, é o efeito do ambiente e da interação genótipo $\mathrm{x}$ ambiente $(\mathrm{GxE})$ na constituição fenotípica de um caráter. A natureza complexa da interação genótipo $\mathrm{x}$ ambiente $(\mathrm{GxE})$ diminui o sucesso com a seleção, pois reduz a correlação entre o fenótipo e o genótipo (COIMBRA et al, 1999; CARMO et al., 2007).

Devido à presença da interação $\mathrm{GxE}$, genótipos com adaptabilidade específica a determinados ambientes poderiam ser recomendados a fim de minimizar o efeito da interação GxE. Entretanto, tal procedimento poderia representar um custo muito elevado ao agricultor, o que poderia tornar sua execução impraticável (PEREIRA et al., 2008). Porém, a identificação de cultivares, com maior estabilidade fenotípica, tem sido uma alternativa muito utilizada para atenuar os efeitos da interação genótipos com ambientes e tornar o processo de indicação de cultivares mais seguro (RIBEIRO et al., 2008).

Nesse sentido, o conhecimento do comportamento de um genótipo frente aos ambientes ao qual está sujeito é fundamental para que o melhorista possa selecionar aqueles menos sensíveis ou insensíveis às variações de ambiente. Em outras palavras, o melhorista busca genótipos com maior valor genotípico em relação aos valores de ambiente e da interação GxE ou aqueles que agreguem todos os componentes fenotípicos positivos. Para verificar isso, são utilizados ensaios com genótipos em mais de um ano e em mais de um local. Destaca-se que a estabilidade na produtividade é um dos aspectos mais relevante em muitas análises, em vários ambientes (PIEPHO, 1999).

Nessa situação, os fatores experimentais (local e ano, por exemplo) devem ser considerados aleatórios, uma vez que os tratamentos são obtidos por amostragem. Efeitos aleatórios são aqueles representativos de uma amostra oriunda de uma determinada população (BARBIN, 1995). Nesse caso, o componente da variância é a variância associada aos efeitos aleatórios do modelo (COIMBRA et al., 2005).
Ao se considerarem os fatores como aleatórios, a estimativa dos componentes da variância é o objetivo maior (BUENO FILHO \& VENCOVSKY, 2000). De acordo com PIEPHO \& MÖHRING (2006), em situações onde há heterogeneidade nas variâncias (devido a perdas de dados, por exemplo), a estimativa adequada dos componentes da variância é necessária na estimação dos efeitos dos genótipos e, nesses casos, quando os efeitos dos genótipos são considerados como aleatórios, o método mais eficaz é o do melhor preditor linear não viesado (BLUP).

Assim, os objetivos deste trabalho foram avaliar os componentes da variância fenotípica para o caráter rendimento de grãos e verificar a sensibilidade genotípica de 12 genótipos de feijão do grupo preto cultivados em 10 ambientes no Estado de Santa Catarina a fim de viabilizar informações para o melhoramento de plantas.

\section{MATERIAL E MÉTODOS}

Foram utilizados dados coletados do Ensaio Estadual de Linhagens e Cultivares de Feijão e do Ensaio de Valor de Cultivo e Uso (VCU), realizados em rede e coordenados pela Empresa de Pesquisa Agropecuária e Extensão Rural de Santa Catarina (EPAGRI) - Centro de Pesquisa para Agricultura Familiar de Chapecó, para o caráter rendimento de grãos. Os ensaios foram conduzidos nas safras agrícolas de 2004/ 05 e 2005/06, nos municípios de Chapecó, Canoinhas, Ituporanga, Lages e Ponte Serrada. A associação ano - local foi considerada um ambiente específico. Do mesmo modo, dentre os diferentes genótipos de feijão cultivados no referido ensaio, 12 foram utilizados neste trabalho: seis linhagens (CHP 9701, CHP 9704, CHP 9858, CHP 9859, CHP 9954 e CHP 9965) e seis cultivares comerciais (IPR Uirapuru, FT Soberano, IPR Graúna, IPR Chopim, BRS Campeiro e Diamante Negro), todos do grupo preto.

O delineamento experimental, em todos os ensaios, foi o de blocos ao acaso, com quatro repetições por tratamento. A densidade de semeadura foi de 15 sementes viáveis por metro linear (250.000 plantas por hectare). A unidade experimental foi constituída por quatro fileiras de $4 \mathrm{x}, 5 \mathrm{~m}$ de comprimento, espaçadas em $0,5 \mathrm{~m}$, e com área útil de $2,7 \mathrm{~m}^{2}$. Para as avaliações dos descritores morfológicos mínimos, foram amostradas 20 plantas da área útil. Para que a cultura não sofresse competição, foi efetuado o controle químico de pragas e plantas invasoras e capina manual conforme a necessidade, ou seja, no momento do início do aparecimento de plantas invasoras. A adubação de base e de cobertura foi realizada de acordo com a análise de solo. 
O modelo estatístico utilizado foi: $V\left(y_{i j k l}\right)=$ $\mu+\sigma^{2} g_{i}+\sigma^{2} a_{j}+\sigma^{2} g a_{i j}+b_{l}+\sigma^{2} \varepsilon_{i j k l}$ em que $\mu$ : média; $g_{i}$ : efeito aleatório do genótipo; $a_{j}$ :efeito aleatório do ambiente; $g a_{i j}$ : efeito aleatório da interação genótipo $\mathrm{x}$ ambiente; $b_{l}$ : efeito do bloco; $\varepsilon_{i j k l}$ : erro; sendo $\mathrm{V}_{(\mathrm{yijkl})}=$ $\mathrm{V}_{\mathrm{F}}$ e $\mathrm{V}_{\mathrm{F}}$ o valor fenotípico.

A estimativa do coeficiente de herdabilidade $\left(\mathrm{h}^{2}\right)$ foi realizada conforme proposto por LITTELL et al. (2006): $\sigma_{f}^{2}=\sigma_{g}^{2}+\sigma_{g}^{2} / G L_{g}+\sigma_{g a}^{2} / G l_{a}+\sigma^{2}{ }_{e} / G L_{g a}$, em que $\sigma_{g}^{2}$ : variância genotípica; $\sigma_{g}^{2}$ : variância de ambiente; $\sigma_{g a}^{2}$ : variância da interação; e $\sigma_{e}^{2}$ : variância do resíduo. $h^{2}=\sigma^{2} g / \sigma_{f}^{2}$, em que $h^{2}$ : herdabilidade; $\sigma^{2} g$ : variância genotípica; e $\sigma_{f}^{2}$ : variância fenotípica.

O procedimento utilizado para a predição de valores genéticos foi o BLUP (melhor predição linear não viesada), utilizando estimativas de componentes de variância dos fatores aleatórios obtidas pelo método da máxima verossimilhança restrita (REML), a partir do comando PROC MIXED para experimentos sob delineamento em blocos ao acaso (LITTELL, et al., 2006). A significância (sensibilidade) dos genótipos aos ambientes foi verificada por meio do espaço de inferência pelo comando ESTIMATE, proposto por McLEAN et al. (1991).

\section{RESULTADOS E DISCUSSÃO}

Os resultados evidenciaram que, na constituição fenotípica do caráter rendimento de grãos (Tabela 1), a maior contribuição pode ser associada com o ambiente $\left(\sigma_{\mathrm{e}}^{2}=728,368\right)$. Por outro lado, a estimativa da variância genotípica foi baixa $\left(\sigma_{\mathrm{g}}^{2}=30,175\right)$. Do mesmo modo, na estimativa da variância da interação GxE, podem ser observados valores baixos $\left(\sigma_{\mathrm{ge}}^{2}=28,756\right)$. De outro ponto de vista, na variância fenotípica do caráter em estudo, 76,05\% podem ser atribuídos ao efeito da variância de ambiente, $3 \%$ ao efeito da variância da interação GxE e 3,15\% ao efeito da variância genotípica. Os resultados estão de acordo com os obtidos por COIMBRA et al. (2008), em que a grande variação entre as médias marginais de 24 genótipos do grupo preto avaliados foi atribuída à variância do ambiente, sendo a estimativa da contribuição genotípica de menor magnitude.

É importante salientar que, para o melhoramento de plantas, o conhecimento da contribuição de cada um dos componentes da variância representa grande importância, de modo que, na seleção de fenótipos superiores, as estimativas da contribuição dos genótipos (G), ambientes (E) e interação GxE são de grande valia, uma vez que existe dependência do fenótipo (F) com esses valores $(\mathrm{F}=\mathrm{G}+\mathrm{E}+\mathrm{GxE})$. $\mathrm{O}$ fenótipo é o resultado das respostas de genótipos específicos para efeitos de ambiente específicos (BURGUEÑO et al., 2008). Também foi verificada uma ampla contribuição dos ambientes na variância fenotípica (Tabela 1), e os valores preditos para ambientes variaram de 1102.68, no ambiente 2 (2005/ Canoinhas), e-1002.85, no ambiente 8 (2006/Lages).

O valor encontrado, na estimativa do coeficiente de herdabilidade, no sentido amplo $\left(\mathrm{h}^{2}\right)$, foi baixo, sendo estimado em 0,15 (Tabela 1 ). Os resultados estão de acordo com os encontrados por GONÇALVESVIDIGAL et al. (2008) e COIMBRA et al. (2009), os quais observaram coeficientes de herdabilidade igualmente baixos para o caráter rendimento de grãos em feijão de 0,23 e 0,21 , respectivamente. A maior parte dos caracteres de importância econômica e agronômica estudados em espécies vegetais é de natureza quantitativa (ALLARD, 1999), fato que explica os baixos valores para a herdabilidade dessas características. De acordo com FALCONER \& MACKAY (1996), o caráter rendimento de grãos é governado por vários genes de pequeno efeito sobre o fenótipo, classificando esse caráter como quantitativo. Embora o rendimento de

Tabela 1 - Estimativas dos componentes da variância dos genótipos, dos ambientes e das interações genótipo $\mathrm{x}$ ambiente, consideradas como efeitos aleatórios, pelo método de máxima verossimilhança restrita (REML), pela estimativa da herdabilidade e pela predição da contribuição de ambiente para a variância fenotípica por meio do melhor preditor linear não viesado (BLUP), em 10 ambientes avaliados no Estado de Santa Catarina, para o caráter rendimento de grãos em feijão do grupo comercial preto.

\begin{tabular}{|c|c|c|c|}
\hline \multirow{2}{*}{\multicolumn{2}{|c|}{ Fatores Aleatórios }} & \multicolumn{2}{|c|}{----------Estimativas---------- } \\
\hline & & Rendimento & $\%$ \\
\hline \multicolumn{2}{|c|}{ Genótipo $\left(\sigma_{\mathrm{g}}^{2}\right)$} & 30,175 & 3,15 \\
\hline \multicolumn{2}{|c|}{ Ambiente $\left(\sigma_{a}^{2}\right)$} & 728,368 & 76,05 \\
\hline \multicolumn{2}{|c|}{ Genótipo x Ambiente $\left(\sigma_{\mathrm{ga}}^{2}\right)$} & 28,756 & 3,00 \\
\hline \multicolumn{2}{|c|}{ Resíduo } & 170,475 & 17,80 \\
\hline \multicolumn{2}{|l|}{ Total } & 957,77 & 100 \\
\hline Ambientes & Ano & Local & Predição \\
\hline 1 & 2004 & Canoinhas & 676,66 \\
\hline 2 & 2005 & Canoinhas & 1102,68 \\
\hline 3 & 2004 & Chapecó & $-781,03$ \\
\hline 4 & 2005 & Chapecó & 9,16 \\
\hline 5 & 2004 & Ituporanga & $-547,73$ \\
\hline 6 & 2005 & Ituporanga & $-672,67$ \\
\hline 7 & 2004 & Lages & $-442,35$ \\
\hline 8 & 2005 & Lages & $-1002,85$ \\
\hline 9 & 2004 & Ponte Serrada & 1001,58 \\
\hline 10 & 2005 & Ponte Serrada & 656,55 \\
\hline \multicolumn{2}{|c|}{ Herdabilidade $\left(h^{2}\right)$} & \multicolumn{2}{|c|}{0,15} \\
\hline
\end{tabular}


grãos seja o caráter agronômico de maior importância para o melhoramento, apresenta como característica marcante baixos valores de herdabilidade (GONÇALVES-VIDIGAL et al., 2008), o que se confirmou também no presente trabalho.

No presente trabalho, foi possível verificar a contribuição de cada um dos componentes da variância para o valor final da variância fenotípica, para o caráter rendimento de grãos (Figura 1). Por exemplo, a linhagem CHP 9701 apresentou uma média final de $3.117 \mathrm{~kg} \mathrm{ha}^{-1}$. Para esse valor, é necessário considerar o valor do genótipo em cada ambiente e no ambiente 1 (2004/Canoinhas), o valor foi de -1,09, que é o efeito do genótipo em si, 676,66 foi o efeito de ambiente 1 (2004/ Canoinhas) e 154,50, o efeito da interação GxE, levando a predição de 830,07 para o referido genótipo. Adicionando esse valor predito à média geral de $3.140 \mathrm{~kg}$ ha $^{-1}$, obtém-se o valor de $3.970 \mathrm{~kg} \mathrm{ha}^{-1}$, que é a função predita para o genótipo nas circunstâncias supracitadas. Considerando que $\mathrm{F}=\mathrm{G}+\mathrm{E}+\mathrm{GxE}$, temos: $\mathrm{F}=(-1,09)+(676,66)+(154,20)=830,07+3.140=3.970 \mathrm{~kg}$ $\mathrm{ha}^{-1}$.

Assim, para o mesmo genótipo; porém, no ambiente 3 (2004/Chapecó), a predição foi de -620,91. Quando esse valor é adicionado à média geral, resulta no valor de $2.519 \mathrm{~kg} \mathrm{ha}^{-1}$. A partir da média dos valores encontrados para o valor fenotípico $(\mu+\rho)$, em todos os ambientes, foi possível obter o valor final do fenótipo, nesse caso: $3.117 \mathrm{~kg} \mathrm{ha}^{-1}$. A partir da média de todos os valores fenotípicos, pode ser obtida a média geral $[(3117.43+3111.36+3202.58+3121.51+3234.38$ $+3194.29+3257.68+3124.89+2912.96+3146.51+$ $\left.3038.42+3218.01) / 12=3.140 \mathrm{~kg} \mathrm{ha}^{-1}\right]$.

A compreensão limitada das consequências dos efeitos de adaptabilidade e de estabilidade fenotípica pelos pesquisadores dificulta sua aplicação como critério de recomendação regionalizada de cultivares superiores (COIMBRA et al., 2009). Por isso, é importante o avanço no conhecimento dos componentes da variância fenotípica para um determinado caráter. Tal entendimento pode contribuir para os programas de melhoramento, podendo, por exemplo, responder algumas questões altamente pertinentes, tais como: i) quais genótipos são promissores; ii) qual o efeito do ambiente e da interação; iii) quais genótipos são menos insensíveis às variações de ambiente; iv) qual a intensidade de seleção a ser praticada e; $v$ ) qual o ganho esperado por seleção.

Os resultados apresentados neste trabalho revelaram a importância do efeito dos componentes da variância $\left(\sigma_{\mathrm{g}}^{2}, \sigma_{\mathrm{e}}^{2}\right.$ e $\left.\sigma_{\text {ge }}^{2}\right)$ na constituição fenotípica do caráter rendimento de grãos, sendo o efeito de ambiente a principal causa nas mudanças no fenótipo (Figura 1). Para todos os ambientes avaliados, houve diferenças significativas entre os genótipos, ou seja, os genótipos responderam de modo diferenciado frente aos ambientes, conforme valores obtidos pela análise do espaço de inferência amplo, conforme proposta por McLEAN et al. (1991).

O modelo utilizado nessa análise permitiu verificar a contribuição da variância genotípica, de ambiente e da interação GxE (Figuras 1 e 2, coluna 1) na constituição fenotípica do caráter rendimento de grãos (Figuras 1 e 2, coluna 2). Conforme ilustrado anteriormente, pode ser estimada a contribuição de todos os componentes da variância para o fenótipo de cada genótipo. Por exemplo, a média observada do genótipo BRS Campeiro (Figura 2g), cultivado no ambiente 1 (2004/Canoinhas), foi de $3.873 \mathrm{~kg} \mathrm{ha}^{-1}$, sendo $\mathrm{F}=5,70+676,66+50,75=733,11+3.140=3.873 \mathrm{~kg} \mathrm{ha}^{-1}$.

Desse modo, é possível verificar qual o componente da variância fenotípica está apontando uma maior contribuição, seja o efeito genotípico, de ambiente ou da interação GxE. Assim, em todos os genótipos avaliados, a contribuição do ambiente foi superior ao efeito genotípico e da interação GxE, exceto para os genótipos CHP 9858 (1c), CHP 9959 (1d), CHP 9965 (1f) e BRS Soberano (2k), todos no ambiente 6 (2005/Ituporanga), onde o efeito da interação foi superior aos demais (Figura 1 e 2, coluna 1). Porém, de modo geral, o aumento ou a redução no rendimento de grãos em todos os genótipos oscilou praticamente em função do efeito de ambiente. Outra revelação relevante dessa análise foi que, quando a contribuição da interação $\mathrm{GxE}$ foi positiva, os valores de rendimento de grãos aumentaram, mesmo diante das contribuições negativas da interação GxE. Por exemplo, para o genótipo IPR Graúna (2j), nos ambientes 3 (2004/ Chapecó), 5 (2004/Ituporanga), 7 (2004/Lages) e 8 (2005/ Lages) (Figura 2j, coluna 1), a contribuição da interação GxE foi positiva, enquanto que a contribuição do ambiente foi negativa.

Embora mesmo havendo uma contribuição positiva da interação GxE, o efeito de ambiente reduziu a média final (Figura $2 \mathrm{j}$, coluna 2). Entretanto, é importante destacar que, quando o efeito do ambiente e da interação GxE foi contrário, porém similar (ambiente 7 - 2004/Lages), o valor do rendimento de grãos (3.074kg $\left.\mathrm{ha}^{-1}\right)$ foi próximo ao da média geral $\left(3.140 \mathrm{~kg} \mathrm{ha}^{-1}\right)$, ou seja, quando os valores do ambiente e da interação GxE se equivalerem (serem muito próximos ou se anularem), o valor fenotípico observado é próximo à média geral (superior ou igual). Tal comportamento pode ser observado nos genótipos BRS Campeiro, no ambiente 5 (1g), IPR Graúna, no ambiente 7 (2004/Lages) 


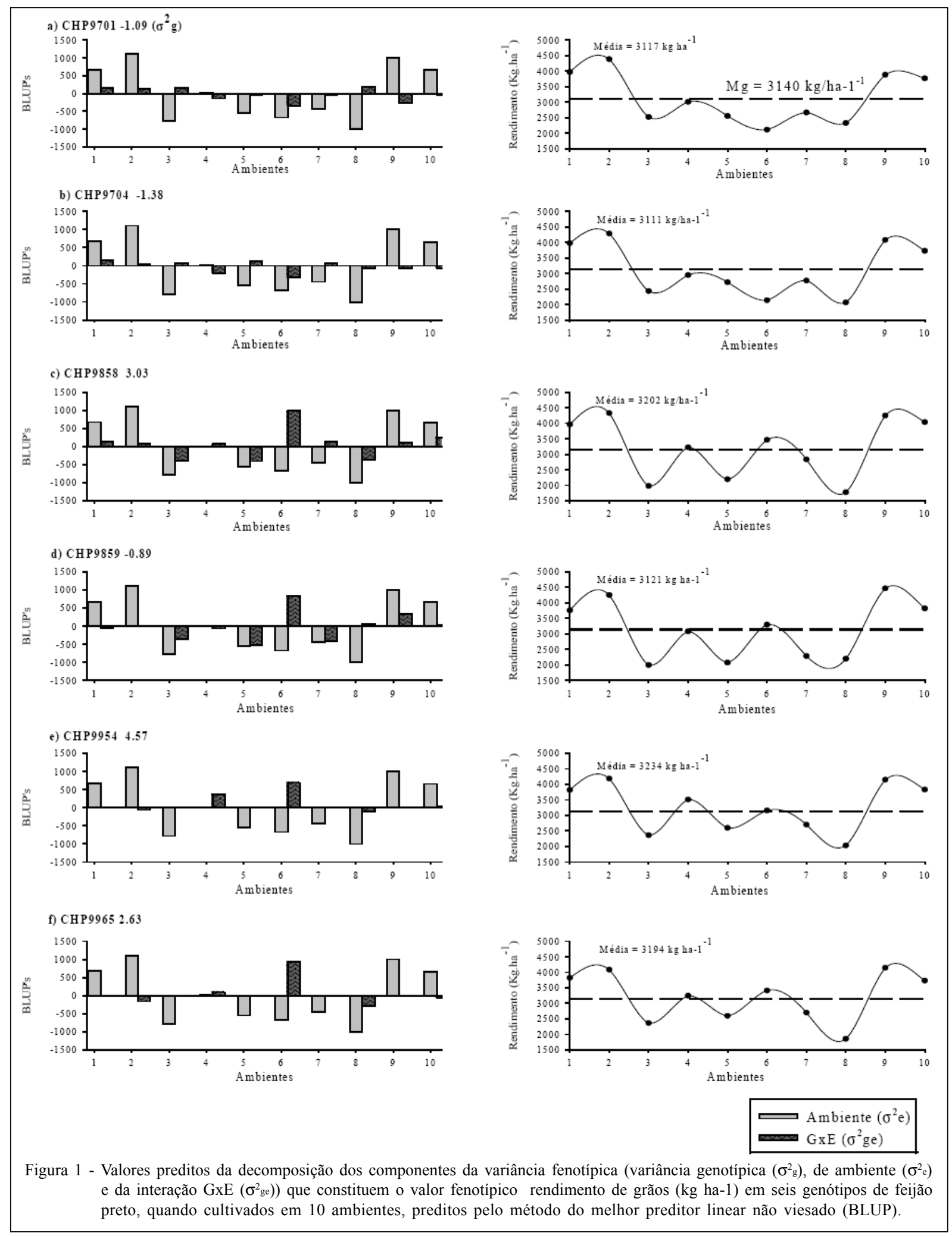

(2j), em praticamente todos os genótipos no ambiente 4 (2005/Chapecó) e nos genótipos CHP 9858 (1c), CHP 9859 (1d), CHP 9954 (1e) e CHP 9965 (1f), no ambiente 6
(2005/Ituporanga). Analisando o genótipo IPR Graúna, no ambiente 2 (2005/Canoinhas), houve uma contribuição positiva, tanto do ambiente, quanto da

Ciência Rural, v.39, n.7, out, 2009. 


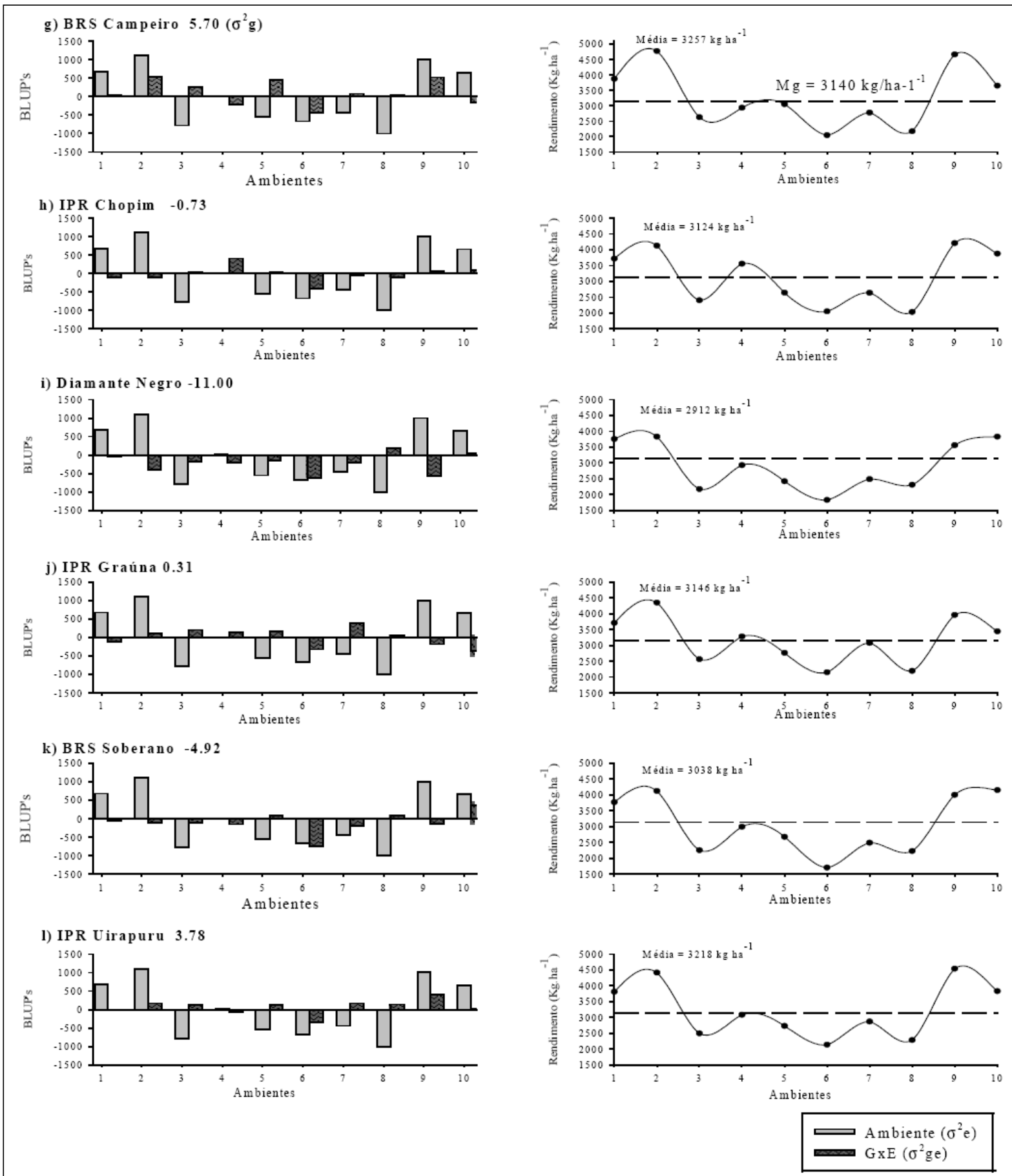

Figura 2 - Valores preditos da decomposição dos componentes da variância fenotípica (variância genotípica $\left(\sigma_{\mathrm{g}}^{2}\right)$, de ambiente $\left(\sigma_{\mathrm{e}}^{2}\right)$ e da interação $\operatorname{GxE}\left(\sigma^{2}{ }_{\mathrm{ge}}\right)$ ) que constituem o valor fenotípico rendimento de grãos $\left(\mathrm{kg} \mathrm{ha}^{-1}\right)$ em seis genótipos de feijão preto, quando cultivados em 10 ambientes, preditos pelo método do melhor preditor linear não viesado (BLUP).

interação GxE, elevando a média do genótipo acima da média geral consideravelmente. Por outro lado, observando o mesmo genótipo nos ambientes 1 (2004/ Canoinhas), 9 (2004/Ponte Serrada) e 10 (2005/Ponte Serrada), pode ser verificado que, quando a interação GxE foi negativa, embora o efeito de ambiente tenha sido positivo, houve uma redução na média do genótipo. Desse modo, ao se comparar o mesmo genótipo nos ambientes 1 (2004/Canoinhas) e 2 (2005/Canoinhas), por exemplo, apesar de ambos serem superiores à média geral (coluna 2), como prevalece o efeito de ambiente, a média desse genótipo, no ambiente 2 (2005/ 
Canoinhas), é superior do que no ambiente 1 (2004/ Canoinhas). Além disso, quando a contribuição do ambiente e da interação GxE foram ambas negativas (ambiente 6 - 2005/Ituporanga), houve uma redução significativa na média final.

Também pode ser constatada uma baixa contribuição das variâncias genotípicas $\left(\sigma_{\mathrm{g}}^{2}\right)$ (Figuras 1 e 2, coluna 1). Assim sendo, foi possível realizar um ranking do efeito das variâncias genotípicas, em que o genótipo com maior valor predito foi o BRS Campeiro (5,70), seguido pelos genótipos CHP $9954(4,57)$, IPR Uirapuru (3,78), CHP 9858 (3,03), CHP99 65 (2,63), IPR Graúna $(0,31)$, todos com contribuição positiva. Por outro lado, os genótipos IPR Chopim (-0,73), CHP 9859 $(-0,89)$, CHP $9701(-1,09)$, CHP $9704(-1,38)$, FT Soberano $(-4,92)$ e Diamante Negro $(-11,00)$ apresentaram valores negativos.

Tais resultados evidenciam que a influência da interação GxE deve ser levada em consideração, em programas de melhoramento, tendo como objetivo alcançar maiores valores de rendimento. Nesse caso, o desejável seria encontrar genótipos que aliem todos os valores de variância (genotípica, de ambiente e de interação) positivos. Assim sendo, pode ser verificado que os genótipos CHP 9701 e CHP 9704, nos ambientes 1 (2004/Canoinhas) e 2 (2005/Canoinhas) (Figuras 1a e 1b, respectivamente), CHP 9858, nos ambientes 1 (2004/ Canoinhas), 2 (2005/Canoinhas), 9 (2004/Ponte Serrada) e 10 (2005/Ponte Serrada) (Figura 1c), CHP 9954, nos ambientes 1 (2004/Canoinhas) e 10 (2005/Ponte Serrada) (Figura 1e), CHP 9965, no ambiente 1 (2004/Canoinhas) e 9 (2004/Ponte Serrada) (Figura 1f), BRS Campeiro, nos ambientes 1 (2004/Canoinhas), 2 (2005/Canoinhas) e 9 (2004/Ponte Serrada) (Figura 2g), IPR Chopim, nos ambientes 9 (2004/Ponte Serrada) e 10 (2005/Ponte Serrada) (Figura 2h), Diamante Negro, no ambiente 10 (2005/Ponte Serrada) (Figura 2i), IPR Graúna, nos ambientes 2 (2005/Canoinhas) e 4 (2005/Chapecó) (Figura 2j), BRS Soberan, no ambiente 10 (2005/Ponte Serrada) (Figura 2k), e IPR Uirapuru, nos ambientes 2 (2005/Canoinhas), 9 (2004/Ponte Serrada) e 10 (2005/ Ponte Serrada) (Figura 21), aliam somente componentes com valores positivos.

Apesar da pequena participação do componente genotípico no valor final do componente fenótipo, a contribuição individual influenciou a média final, ou seja, os genótipos que obtiveram maiores valores preditos foram os que revelaram maiores médias de rendimento. Ou seja, o genótipo BRS Campeiro apresentou uma média de $3.257 \mathrm{~kg} \mathrm{ha}^{-1}$, que, em parte, se deve ao efeito individual do genótipo, nesse caso, positivo $(5,70)$. Entretanto, o genótipo Diamante Negro apresentou uma média de $2.912 \mathrm{~kg} \mathrm{ha}^{-1}$, ou seja, a menor média de todos os genótipos, uma vez que seu valor predito foi negativo $(-11,00)$, o que pode ter influenciado o valor final de rendimento de grãos final. Entre os genótipos avaliados a partir da decomposição dos componentes da variância fenotípica, o BRS Campeiro foi o que apresentou maior média de rendimento de grãos $\left(3.257 \mathrm{~kg} \mathrm{ha}^{-1}\right)$ e ainda o maior valor predito $(5,70)$. Além disso, o genótipo poderia ser recomendado para a maior parte dos ambientes avaliados, exceto para os ambientes 3 (2004/Chapecó), 6 (2005/Ituporanga), 7 (2004/Lages), e 8 (2005/Lages) (Figura 2g), uma vez que revelou valores abaixo da média geral. Por meio da figura 1, pode ser observado que os genótipos CHP 9858, CHP 9859, CHP 9954 e CHP 9965 foram os únicos que revelaram valores iguais ou acima da média para rendimento de grãos no ambiente 6 (2005/Ituporanga). Tal fato pode estar revelando uma adaptabilidade a ambientes específicos, podendo ser recomendados para os ambientes descritos anteriormente. Outra informação extremamente útil em termos de melhoramento genético vegetal é distinguir em quais ambientes o melhorista pode conduzir e avaliar suas populações segregantes sem que haja uma interferência forte em termos de fenótipo ocasionada pelo efeito não genético, ou seja, de ambiente (COIMBRA et al., 2009). Assim sendo, os ambientes 1 (2004/Canoinhas), 2 (2005/ Canoinhas), 9 (2004/Ponte Serrada) e 10 (2005/Ponte Serrada) propiciaram um valor de rendimento de grãos acima da média geral em todos os genótipos avaliados. Isso significa que, antes da recomendação de uma nova cultivar para Santa Catarina, seriam necessários, pelo menos, testes em dois anos e em quatro locais.

$\mathrm{O}$ fato de que o efeito de ambiente foi dramaticamente superior ao efeito genotípico também indica que há oportunidade para o melhoramento genético. Assim, novas associações alélicas poderiam ser desenvolvidas e testadas nesses locais, explorando a interação genótipo e ambiente (GxE) a fim de aumentar a produtividade por área, mas agora com base num genótipo superior, o qual poderia ser recomendado para ambientes específicos.

Os métodos clássicos no melhoramento de plantas são fundamentados no fato de que o fenótipo é o resultado da ação conjunta e independente do genótipo e do ambiente, expressa em termos de suas variâncias associadas aos efeitos dos fatores aleatórios (COIMBRA et al., 2008). De modo que o entendimento dos fatores que constituem o fenótipo pode ser de fundamental importância para os programas de melhoramento, possibilitando ao melhorista/ pesquisador selecionar indivíduos em função dos maiores valores genéticos preditos, ou seja, os indivíduos que apresentarem maiores variâncias 
genéticas. A quantificação da variabilidade genética é importante em programas de melhoramento porque revela a estrutura genética da população (CEOLIN et al., 2007). CHIORATO et al. (2008), avaliando genótipos de feijão, concluíram que, dentre 18 genótipos avaliados, nove apresentaram valores genotípicos preditos superiores à média geral. Desse modo, com base na variância genotípica, podem ser selecionados os genótipos com o ideótipo de planta desejado, ou ainda, aqueles em que há existência de interação $\mathrm{GxE}$, os quais são recomendados para ambientes específicos.

\section{CONCLUSÕES}

A decomposição dos componentes da variância fenotípica permitiu ampliar as inferências dos resultados obtidos para o caráter rendimento de grãos. O genótipo BRS Campeiro foi o que apresentou maior média de rendimento de grãos e o maior valor predito, podendo ser indicado para a maior parte dos ambientes avaliados. Os ambientes 1 (2004/Canoinhas), 2 (2005/ Canoinhas), 9 (2004/Ponte Serrada) e 10 (2005/Ponte Serrada) propiciaram um valor de rendimento de grãos acima da média geral em todos os genótipos avaliados. Os genótipos CHP 9858, CHP 9859, CHP 9954 e CHP 9965 revelaram uma adaptabilidade específica ao ambiente 6 (2005/Ituporanga).

\section{AGRADECIMENTOS}

Agradecemos à Universidade do Estado de Santa Catarina (UDESC), à Coordenação de Aperfeiçoamento de Pessoal de Nível Superior (CAPES), ao Conselho Nacional de Desenvolvimento Científico e Tecnológico $(\mathrm{CNPq})$ e à Fundação de Apoio à Pesquisa Científica e Tecnológica do Estado de Santa Catarina (FAPESC), pela concessão de bolsa e apoio financeiro.

\section{REFERÊNCIAS}

ALLARD, R.W. Principles of plant breeding. New York Wiley, 1999. 257p.

BARBIN, D. Componentes de variância - Teoria e aplicações. 2.ed. Piracicaba: FEALQ, 1995. 120p.

BUENO FILHO J.S.S.; VENCOVSKY, R. Alternativas de análise de ensaios em látice no melhoramento vegetal. Pesquisa Agropecuária Brasileira, v.35, p.259-269, 2000. Disponível em: <http://webnotes.sct.embrapa.br/pab/pab.nsf/FrAnual> Acesso em: 20 nov. 2008.

BERTOLDO, J.G. et al. Efeito de diferentes concentrações salinas na redução do tempo de cocção de feijão (Phaseolus vulgaris L.). Biotemas, v.21, p.39-44, 2008. Disponível em: $<$ http://www.biotemas.ufsc.br/volumes/pdf/volume213/ p39a44.pdf> Acesso em: 20 nov. 2008.
BURGUEÑO, J. et al. Using factor analytic models for joining environments and genotypes without crossover genotype $\mathrm{x}$ environment interaction. Crop Science, v.48, p.1291-1305, 2008. Disponível em: <http://crop.scijournals.org/cgi/reprint/ 48/4/1291>. Acesso em: 21 nov. 2008. doi: 10.1016/S0022474X(00)00016-3.

CARMO, S.L.M. et al. Avaliação do stay green em famílias segregantes de feijão (Phaseolus vulgaris L.) Ciência e Agrotecnologia, v.31, p.953-957, 2007.

CEOLIN, A.C.G. et al. Genetic divergence of the common bean (Phaseolus vulgaris L.) group Carioca using morpho-agronomic traits by multivariate analysis. Hereditas, v.144, p.1-9, 2007. Disponível em: <http://www3.interscience.wiley.com/journal/ 117972147/abstract?CRETRY $=1 \&$ SRETRY $=0>$ Acesso em: 23 nov. 2008. doi: 10.1111/j.2006.0018-0661.01943.

CHIORATO, A.F. et al. Prediction of genotypic values and estimation of genetic parameters in common bean. Brazilian Archives of Biology and Technology, v.51, p.465-472, 2008. Disponível em: <http://www.scielo.br/pdf/babt/v51n3/ a05v51n3.pdf $>$ Acesso em: 22 nov. 2008.

COIMBRA, J.L.M. et al. Reflexos da interação genótipo x ambiente e suas implicações nos ganhos de seleção em genótipos de feijão (Phaseolus vulgaris L.). Ciência Rural, v.29, p.433439, 1999. Disponível em: <http://www.scielo.br/ scielo.php? script=sci_abstract \& pid=S0103$84781999000300009 \& \operatorname{lng}=\mathrm{pt} \& \mathrm{nrm}=\mathrm{iso} \& \mathrm{t} \operatorname{lng}=\mathrm{pt}>$. Acesso em: 23 nov. 2008. doi: 10.1590/S0103-84781999000300009.

COIMBRA, J.L.M. et al. Prediction of the genetic value in populations F3 of Avena sativa L. using REML/BLUP. Crop Breeding and Applied Biotechnology, v.5, p.125-133, 2005.

COIMBRA, J.L.M. et al. Seleção para caracteres adaptativos em acessos de feijão usando REML/BLUP. Magistra, v.20, p.177-185, 2008 .

COIMBRA, J.L.M. et al. Mineração da interação genótipo x ambiente em Phaseolus vulgaris L. para o Estado de Santa Catarina. Ciência Rural, v.39, p.355-363, 2009. Disponível em: <http://www.scielo.br/ scielo.php?pid $=\mathrm{S} 0103-84782008005000069 \&$ script $=$ sci arttext $>$ Acesso em: 15 nov. 2008. doi: 10.1590/S0103-84782008005000069.

FALCONER, D.S.; MACKAY, T.F.C. Introduction to quantitative genetics. 4.ed. England: Longman, 1996. 463p.

GONÇALVES-VIDIGAL, M.C. et al. Heritability of quantitative traits in segregating common bean families using a Bayesian approach. Euphytica, v.164, p.551-560, 2008. Disponível em: $<$ http://www.springerlink.com/content/4573650254385315>. Acesso em: 15 nov. 2008. doi: 10.1007/s10681-008-9758-6.

LITTELL, R.C. et al. SAS System for Mixed Models. Cary: Statiscal Analysis System Institute, 2006. 633p.

McLEAN, R.A. et al. A unified approach to mixed linear models. American Statistician, v.45, p.54-64, 1991.

MOOSE, S.P.; MUMM, R.H. Molecular PLANT breeding as the foundation for $21^{\text {st }}$ Century crop improvement. Plant Physiology, v.147, p.969-977, 2008. Disponível em: <http:/ 
/www.plantphysiol.org/cgi/content/full/147/3/969>. Acesso em: 16 nov. 2008. doi: 10.1104/pp.108.118232.

PEREIRA, D.V. et al. Adaptabilidade e estabilidade de genótipos de soja avaliados para resistência ao oídio. Ciência Rural,

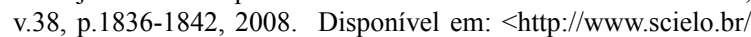
scielo.php? script=sci_abstract \& pid=S 0103 $84782008000700006 \& \operatorname{lng}=\mathrm{pt} \& \mathrm{nrm}=\mathrm{iso} \& \mathrm{t} \operatorname{lng}=\mathrm{pt}>$. Acesso em: 16 nov. 2008. doi: 10.1590/S0103-84782008000700006.

PIEPHO, H.P. Stability Analysis Using the SAS System. Agronomy Journal, v.91, p.154-160, 1999.
PIEPHO, H.P.; MÖHRING, J. Selection in cultivar trials-Is it ignorable? Crop Science, v.46, p.192-201, 2006. Disponível: $<$ http://crop.scijournals.org/cgi/content/abstract/46/1/192>. Acesso em: 18 nov. 2008. doi: 10.2135/cropsci2005.04-0038

RIBEIRO, N.D. et al. Adaptação e estabilidade de produção de cultivares e linhagens-elite de feijão no Estado do Rio Grande do Sul. Ciência Rural, v.38, p.2434-2440, 2008. Disponível em: $<$ ht t p://www.scielo.br/s cielo.php? pid=S $0103-$ $84782008005000018 \&$ script $=$ sci_abstract\&tlng=e $>$. Acesso em: 18 nov. 2008. doi: 10.1590/S0103-84782008005000018.

Ciência Rural, v.39, n.7, out, 2009. 